\title{
UTILIZAÇÃO DO GOOGLE FORMS COMO FERRAMENTA DIDÁTICA-PEDAGÓGICA PARA O ENSINO DE FLUXOGRAMAS DE ENGENHARIA DE TUBULAÇÃO E INSTRUMENTAÇÃO (P\&ID)
}

João Paulo da S. Q. Menezes - joaomenezes@ @eq.ufrj.br

Universidade Federal do Rio de Janeiro, Departamento de Engenharia Química (DEQ/UFRJ) Escola de Química, Centro de Tecnologia, Bloco E Av. Athos da Silveira Ramos, 149 - Ilha do Fundão CEP - 21941-909 - Rio de Janeiro - RJ

Roberto B. de Carvalho - rbcarvalho@ puc-rio.br

Pontifícia Universidade Católica do Rio de Janeiro, Coordenação do Ciclo Profissional das Engenharias (CCPE/PUC-RIO)

Endereço: Rua Marquês de São Vicente, 225, Gávea

CEP: 22453-900 - Rio de Janeiro - RJ

Resumo: A adoção de estratégias ativas de ensino é recomendada pelas novas diretrizes curriculares para os cursos de engenharia. Nesse sentido, o avanço da tecnologia possibilita a utilização de novas ferramentas e aplicativos pedagógicos para intensificar o processo de aprendizagem. Nesse trabalho, a plataforma Google Forms foi utilizada para elaboração de formulários sobre o aprendizado dos alunos de Projeto de Processos Químicos, disciplina dedicada a elaboração de Projetos de Engenharia em Equipe. Os tópicos escolhidos para serem avaliados foram os desenhos de engenharia, mais especificamente os Fluxogramas de Engenharia de Tubulação e Instrumentação (P\&ID), devido ao seu maior nível de complexidade e detalhamento. Foram elaborados dois Formulários e aplicados na turma de 2020.1, composta de 11 alunos. O primeiro, contendo doze perguntas de múltipla escolha, foi sobre as diferentes áreas e conectores do P\&ID e o segundo, contendo dezesseis perguntas de verdadeiro ou falso, foi sobre a representação completa no P\&ID da malha de controle especifica de temperatura via válvula de controle. A utilização da ferramenta apresentou resultados promissores e uma boa aceitação por parte dos alunos, devido a sua interface gráfica simples e devido à variedade de funções disponíveis para o docente, incluindo a importação de recursos multimídia e a apresentação de resultado estatístico detalhado das respostas. As médias de acertos dos formulários foram de 97,0 e 93,2 \%, respectivamente, indicando que os alunos estão habilitados previamente para construção do P\&ID do Projeto de Engenharia em equipe.

Palavras-chave: P\&ID. Google Forms. Metodologia Ativa. 


\section{INTRODUÇÃO}

De acordo com as novas Diretrizes Curriculares para o curso de engenharia (DCNs), a adoção de metodologias ativas de aprendizagem, nas quais os alunos são protagonistas e participam efetivamente do processo de construção do aprendizado, devem ser incentivadas e adotadas nos cursos de graduação (Oliveira, 2019). No entanto, muitos avanços ainda são necessários para superar as metodologias convencionais, nas quais o aluno é meramente um receptor passivo de informações transmitidas pelos docentes em sala de aula e não há um acompanhamento individual e efetivo de cada discente.

Nesse contexto, plataformas para criação de formulários eletrônicos, como por exemplo o Google Forms, pode ser uma poderosa ferramenta didático-pedagógica, auxiliando no treinamento dos alunos de Projetos de Processos Químicos, em uma etapa anterior a realização dos Projetos de Engenharia propriamente ditos praticados na metodologia de ensino ativa. Essas ferramentas permitem a elaboração de formulários sobre tópicos abordados em sala de aula, permitindo a importação de recursos multimídia, como imagens e vídeos do Youtube, e atribuição de pontuação por questão. Além disso, os formulários podem ser aplicados como uma pesquisa de opinião, com o objetivo de promover a autoavaliação do aprendizado pelo aluno e identificar principais tópicos de interesse.

O aplicativo ainda fornece ao docente um resultado detalhado das respostas do formulário, incluindo as respostas erradas com maior frequência e a porcentagem de acertos em cada questão, o que proporciona um feedback do aprendizado dos alunos ao docente. Dessa forma, há um acompanhamento individual de cada aluno, identificando-se as principais áreas deficientes e os principais interesses sobre determinando tema. Essas informações são valiosas, pois auxiliam o docente na elaboração de planos e estratégias de atuação.

Farias (2017) apresenta os recursos disponibilizados pela Google Apps for Education como ferramenta colaborativa para a ação docente. Uma vantagem dessa plataforma é que todo o conteúdo pode ser acessado a qualquer momento, de qualquer dispositivo, pois todo o material didático fica armazenado em nuvem de forma segura, com uma capacidade de armazenamento gratuito de $15 \mathrm{~Gb}$. De acordo com os autores, a utilização do Google Forms tem grande valor para o professor como fonte de avaliação, pesquisa e acompanhamento junto aos seus alunos. Nesse sentido, o professor pode fazer um questionário individualizado que exibe a quantidade de acertos de cada aluno.

Santos (2020) reporta que os formulários do Google se apresentaram como uma das ferramentas mais eficientes nesse contexto do ensino remoto devido a pandemia do novo coronavírus. Os autores entrevistaram vários especialistas e educadores, os quais reportaram diversas facilidades oferecidas pelo aplicativo, como modelos prontos para avaliações, inserção de fotos e vídeos, possibilidade de formulação de perguntas discursivas ou objetivas, facilidade de registro e controle das respostas e possibilidade de correção automática ou manual. Além disso, os educadores reportaram um feedback positivo pela maioria dos alunos, devido a interatividade, praticidade e atratividade que o aplicativo oferece.

Nesse trabalho, o aplicativo Google Forms foi utilizado na disciplina de Projeto de Processos Químicos para intensificar o aprendizado sobre Fluxograma de Engenharia de Tubulação e Instrumentação (P\&ID). O P\&ID é um desenho de engenharia 2D que apresenta o processo químico com um maior grau de detalhamento, pois além da especificação de todos os equipamentos, correntes, instrumentos e malhas de controle, também pode-se observar a especificação de toda a parte hidráulica, elétrica e de automação, com detalhamento das malhas de controle e intertravamento do processo (Bassane et al., 2019 e Carvalho et al., 2019). Dessa forma, devido a sua complexidade, a utilização de recursos de mídia, exemplificando P\&IDs 
de processos reais, é muito importante para facilitar a visualização das diferentes áreas do fluxograma e intensificar o processo de aprendizagem.

Além disso, esse trabalho tem o objetivo de promover o estudo dos desenhos de engenharia nos cursos de graduação de Engenharia Química, visto que o mercado demanda profissionais com a habilidade de realizar um projeto completo de engenharia, desde a fase conceitual até a etapa de operação e manutenção dos equipamentos (Tamietti, 2009). No entanto, apesar da sua importância, pouco destaque é dado aos desenhos de engenharia nos cursos de graduação, os quais priorizam as memórias de cálculo dos balanços de massa e energia, bem como as tecnologias envolvidas. Assim, o trabalho visa auxiliar o preenchimento desse gap no ensino de Engenharia Química, aliando-se ao uso de novas tecnologias, em especial o Google Forms.

\section{METODOLOGIA}

\subsection{ASPECTOS GERAIS}

Foram construídos dois diferentes formulários do Google Forms envolvendo assuntos relativos à aprendizagem do Fluxograma de Engenharia, Tubulação e Instrumentação (P\&ID). No primeiro, mostrou-se uma visão ampla do P\&ID, trabalhando as diferentes áreas do desenho e os tipos de conectores principais. No segundo, buscou-se apresentar a representação completa de malhas de controle específicas de temperatura, via válvula de controle, conforme detalhado no tópico seguinte.

O primeiro formulário foi desenvolvido através de perguntas de múltipla escolha, com quatro alternativas disponíveis, envolvendo as diferentes áreas do P\&ID, os tipos de conectores do desenho, documentos de engenharia e outros termos normalmente presentes no vocabulário de projetos de engenharia. Esse primeiro formulário pode ser acessado pelo link: https://forms.gle/bR5vdu2t8jDzRpKc7. O segundo formulário foi elaborado contendo dezesseis perguntas de verdadeiro ou falso sobre a malha de controle de temperatura e pode ser acessado pelo link: https://forms.gle/86y5BebBp27HosMH8.

Os formulários foram submetidos como parte da avaliação da disciplina de Projeto de Processos Químicos da PUC/RJ e foram respondidos por todos os 11 alunos matriculados na disciplina. Os resultados apresentados foram obtidos através dos recursos de feedback do google forms, dentre os quais estão a porcentagem média de perguntas acertadas, perguntas erradas com maior frequência e distribuição de acertos dos alunos. Essas estatísticas foram utilizadas para comentar com cada aluno os erros cometidos no formulário.

\subsection{DETALHAMENTO DOS FLUXOGRAMAS NOS FORMULÁRIOS}

A Figura 1 mostra o P\&ID do processo de desidratação. Esse fluxograma foi construído em projetos de engenharia de períodos anteriores na disciplina de Projeto de Processos Químicos, utilizando o programa open source Draw io.

Na Figura 1, os números de 1 a 9 indicam as diferentes áreas do P\&ID: área gráfica (1), área de tabela com status operacional do processo (2), área de referências (3), área de lista de equipamentos (4) e área de simbologia (5), área de nota e legendas (6), área de revisão (7), área de títulos (8) e áreas de grid (9). Já os números de 10 a 12 indicam os diferentes tipos de conectores presentes no P\&ID: conector de fluido de entrada (10), conector de fluido de saída ou final de linha (11) e conector entre desenhos (12). 


\section{COBENCE e III Simpósio Internacional}

"Os desafios para formar hoje o engenheiro do amanhã"

Figura 1: Fluxograma de Engenharia de Tubulação e Instrumentação do processo de desidratação do gás natural utilizando peneiras moleculares.

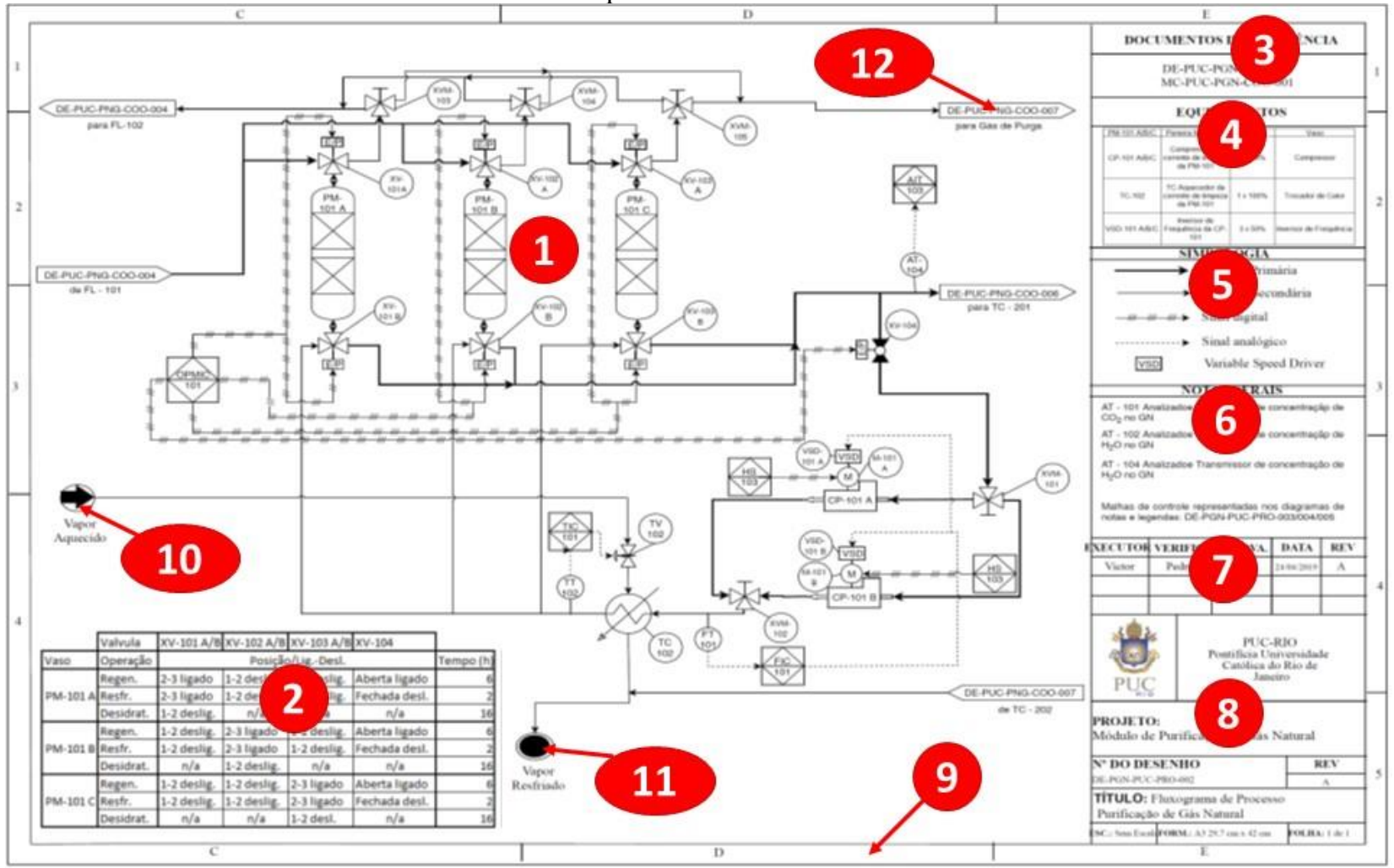

Fonte: Acervo próprio

A área gráfica é o local do P\&ID onde é apresentado o desenho do processo propriamente dito. Por ser o desenho de engenharia 2D mais detalhado, toda a parte de tubulação e de instrumentação são detalhadas no P\&ID, com todos os equipamentos, linhas hidráulicas, válvulas, instrumentos, sinais e dispositivos elétricos e de automação representados, cada um com suas figuras pictóricas.

Os fluidos que entram ou saem do processo no P\&ID específico devem ser representados por conectores próprios. Na Figura 1, por exemplo, podem ser identificados: o fluido de entrada de vapor aquecido, conector identificado pelo número 10, que faz o serviço de aquecimento do gás tratado utilizado para regeneração das peneiras moleculares; e o fluido de saída de vapor resfriado, conector identificado pelo número 11, que é a saída do fluido de aquecimento usado na troca térmica indireta pelo trocador de calor.

Dado o seu grau de detalhamento, cada P\&ID representa uma parte pequena do processo, com conectores entre desenhos indicando a entrada e saída de correntes de/para outros P\&IDs, com equipamento de origem ou destino da corrente também identificados abaixo do conector. $\mathrm{Na}$ Figura 1, por exemplo, o conector entre desenho, identificado pelo número 12, indica a corrente de gás de purga que é encaminhada para o desenho DE-PUC-PNG-COO-007.

A origem dos diferentes P\&IDs é o Fluxograma de Processo (PFD), que contém a representação simplificada do processo com todo o balanço de massa e energia apresentado, sem o detalhamento completo das tubulações e instrumentos. Os conectores entre desenhos são empregados com intuito de montar um quebra-cabeça, a junção de todos os P\&IDs daria um grande PDF com todo o detalhamento do processo, sendo necessário garantir a consistência dos 
diferentes fluidos e correntes. Nesse sentido, a área de Grid, identificado pelo número na Figura 1, exerce um papel importantíssimo. A origem completa do Grid é definida a partir do PFD, ao detalhar uma parte do processo em um P\&ID específico, o Grid desse P\&ID deve ser o mesmo local que a sua área gráfica se localiza no PFD.

A área de tabela com status operacional do processo, identificada pelo número 2 na Figura 1 , representa de forma direta as diferentes operações do processo e suas automações. No P\&ID modelo apresentado, por exemplo, temos três vasos com peneiras moleculares operados automatizados por válvulas esferas três vias automáticas. No processo temos sempre dois vasos realizando o processo de desidratação do gás natural e um dos vasos em regeneração, para remover a água adsorvida durante a desidratação. A etapa de regeneração é composta por uma etapa de regeneração, onde o vaso é aquecido pela passagem de gás tratado quente, e a etapa de resfriamento. Observa-se na tabela que, em cada vaso, a desidratação ocorre por um tempo de 16 horas, com 6 horas na etapa de regeneração e 2 horas na etapa de resfriamento. A defasagem em cada vaso nos horários das diferentes etapas possibilita operação contínua do processo, sempre com dois vasos na etapa de desidratação. Nota-se também na tabela do status operacional as posições hidráulicas de cada válvula 3 vias, nas diferentes etapas do processo.

A área de documentos de referência, identificada pelo número 3 na Figura 1, apresentam os outros documentos de engenharia utilizados como base para construção do P\&ID específico. Dentre os documentos de referência, destaca-se o PFD. A memória de cálculo de linhas e o memorial descritivo de processo final são outros documentos de referência comuns dos P\&IDs. Ainda é possível optar pelo detalhamento completo de algumas malhas de controle ou intertravamento específicas em P\&ID’s de Notas Gerais, nos quais a representação completa da malha é apresentada e, em seguida, indica-se uma representação simplificada da tal malha. Assim, os P\&IDs de Notas Gerais devem ser documentos de referências para os P\&IDs do processo. Por fim, todos os P\&IDs de processo dos quais existem correntes entrando ou saindo, devem também ser citados como documentos de referência.

A área de lista de equipamentos, identificada pelo número 4 na Figura 1, mostra os dados principais dos equipamentos presentes no P\&ID, apresentados na forma de uma tabela contendo: o TAG, descrição, quantidades e capacidades. Essas informações são originadas de um resumo da Lista de Equipamento, um documento de engenharia específico, com dados mais completos, bem como das diferentes memórias de cálculo, que determinam, através dos princípios fundamentais da engenharia, as características dos diferentes equipamentos.

A área de simbologia, identificada pelo número 5 na Figura 1, mostra as principais simbologias utilizadas na área gráfica do P\&ID.

Já a área de revisão, identificada pelo número 6 na Figura 1, apresenta todas as versões geradas do desenho, com descrições dos executores, revisores e aprovadores, bem como indicação das datas de cada evento, o que garante a rastreabilidade de todo o projeto de engenharia.

Outra área, indicada pelo número 7 na Figura 1, seria a Área de Notas e Legendas, onde realiza-se a descrição de algo que seja muito difícil representar graficamente. Um exemplo seria as identificações dos diferentes Analisadores/Transmissores Analíticos presentes no processo, vistos que todos recebem o TAG AT.

Por fim, temos a área de títulos, identificada pelo número 8 na Figura 1. Aqui são descritas todas as informações principais do projeto, tais como: nome do projeto, nome do cliente, nome do empreendimento, nome do desenho, escala do desenho, dentre outras.

A Figura 2 mostra a representação completa de uma malha de controle de temperatura via válvula de controle de temperatura, que pode ser feita em um P\&ID de Notas Gerais. Esse tipo de malha está presente, por exemplo, na desidratação do gás natural por peneiras moleculares 
para aquecer o gás tratado que realiza a regeneração das peneiras, como mostrado na área gráfica do P\&ID apresentado na Figura 1.

Figura 2: Representação completa no P\&ID de Notas Gerais de uma malha de controle de temperatura via válvula de controle de temperatura, sem identificação do sentido das informações dos sinais e do trocador de calor, presente na troca térmica indireta das correntes hidráulicas representadas.

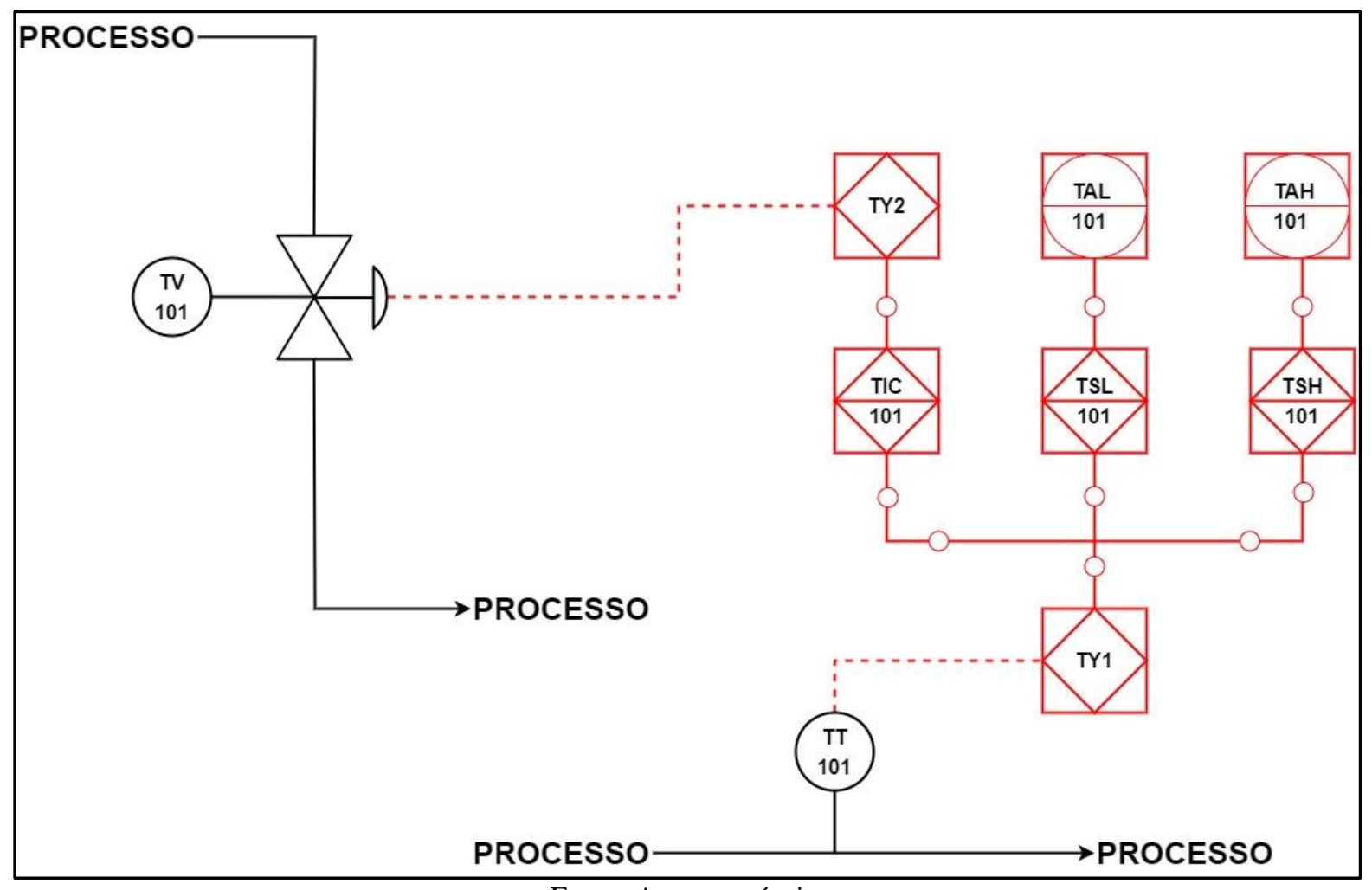

Fonte: Acervo próprio.

Com base na malha apresentada na Figura 2, que representa o aquecimento, pela troca térmica indireta, da corrente de gás tratado que realiza a regeneração das peneiras moleculares, o segundo formulário do Google Forms foi elaborado.

O objetivo desse segundo formulário foi exercitar no aluno a identificação em campo da válvula de controle de temperatura (TV 101) e do transmissor de temperatura (TT 101), bem como o reconhecimento dos tipos de sinais (analógicos, digitais ou lógicos) através das diferentes linhas utilizadas (tracejada, inteira com três traços na diagonal ou traço-bola), conforme padronização pelas normas de Elaboração de Projeto de Engenharia (Tamietti, 2009).

Foi desejado também trabalhar a identificação se o sinal era de entrada ou de saída, tendo como referencial o Controlador Lógico Programável (CLP), bem como a identificação dos cartões de memória que interligam os instrumentos em campo ao CLP (TY1 e TY2).

Além disso, no formulário foram feitas também perguntas relacionadas as direções dos sinais, identificação da representação das chaves de temperatura alta (TSH 101) e de temperatura baixa (TSL 101) presentes no CLP e localização da representação dos alarmes de temperatura alta (TAH 101) e de temperatura baixa (TAL 101) presentes no sistema supervisório. 


\section{RESULTADO}

As Figuras 3 e 4 apresentam os resultados obtidos de pontuações, disponibilizado pelo próprio aplicativo. Observa-se ainda que o aplicativo calcula a média e a mediana automaticamente, além de apresentar relatórios, contendo as perguntas erradas com maior frequência e o número de acertos por pergunta. Essas informações podem servir como feedback do aprendizado do aluno, guiando o docente na elaboração de estratégias para intensificar o aprendizado.

Figura 3: Distribuição das pontuações dos alunos no formulário referente as áreas e aos conectores do P\&ID.

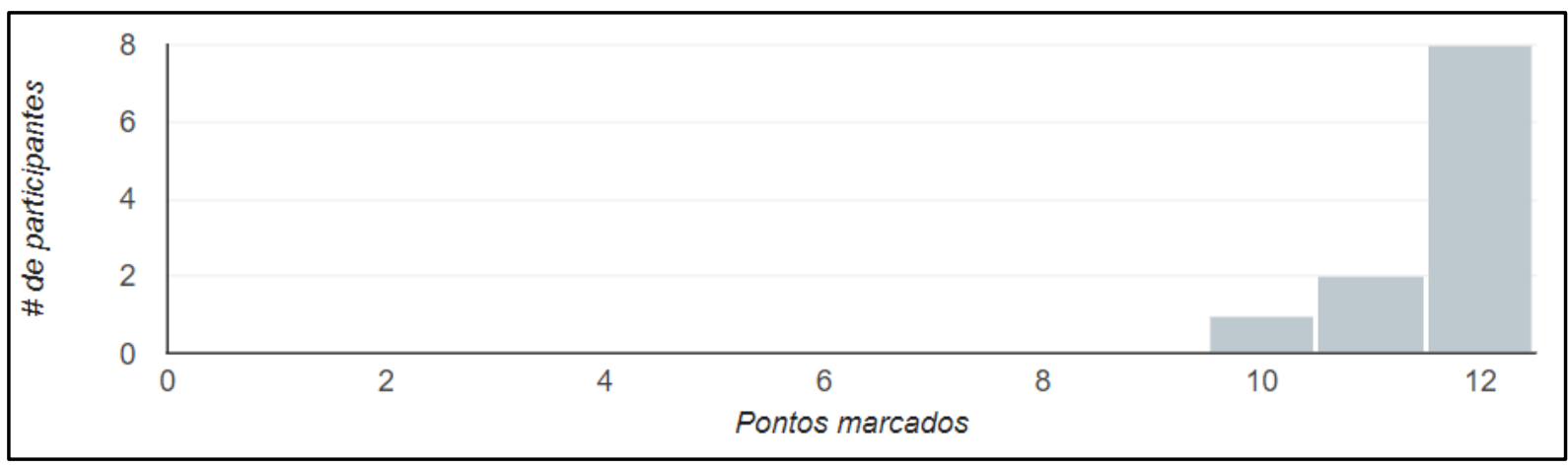

Fonte: Acervo próprio.

No formulário sobre as diferentes áreas e conectores do P\&ID, apresentado na Figura 3, observou-se que houve um acerto médio de $97,0 \%$ das perguntas realizadas. Verificou-se que oito das doze perguntas realizadas foram acertadas por todos os alunos. Nas quatro demais perguntas houve apenas um erro nas respostas enviadas. Os erros observados foram nas perguntas sobre os conectores de fluidos de entrada e de saída, a área gráfica e a área de equipamentos. Ao passar o feedback dos erros para os alunos foi possível constatar pequenas desatenções como causa dos erros ocorridos.

Figura 4: Distribuição das pontuações dos alunos no formulário referente a malha de controle completa de temperatura via válvula de controle.

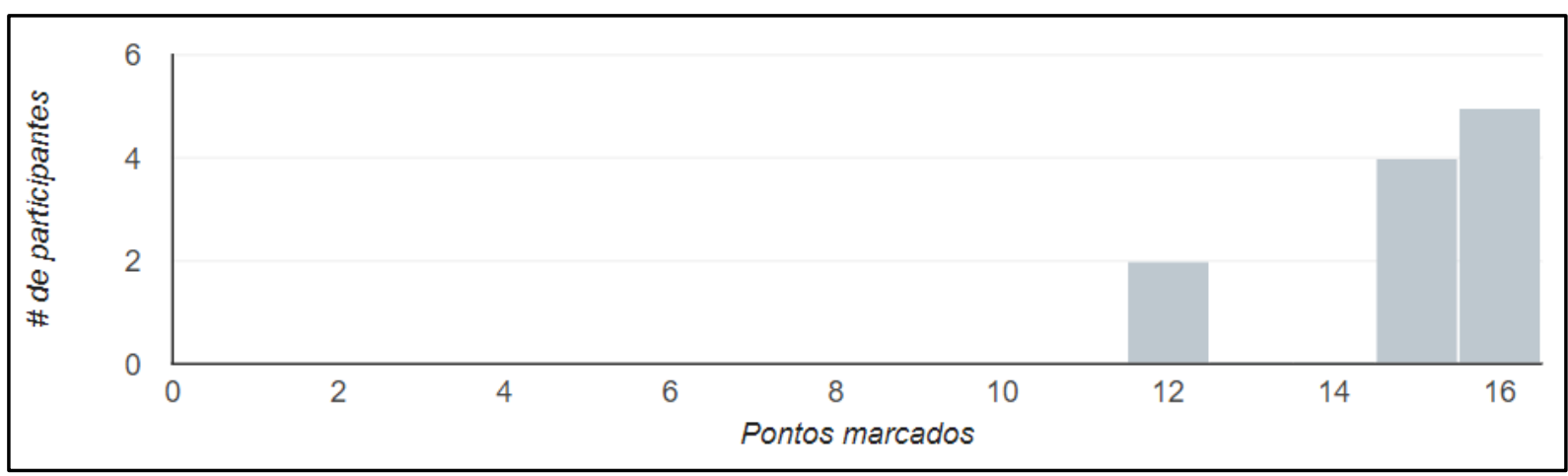

Fonte: Acervo próprio.

No formulário sobre a representação no P\&ID da malha completa de controle de temperatura via válvula de controle, apresentado na Figura 4, observou-se que houve um acerto médio de 93,2 \% das perguntas realizadas. Todos os alunos acertaram seis das dezesseis 
perguntas elaboradas. Em oito das perguntas verificou-se apenas um erro, sendo as temáticas relativas ao:

- Tipo do sinal do transmissor de temperatura (analógico de entrada);

- Sentido do sinal do transmissor de temperatura (do transmissor para o cartão de memória);

- Significado do alarme de temperatura alta no supervisório (TAH 101);

- Tipos de cartão de memória presentes na malha (TT 101: cartão de entrada analógica e TV 101: cartão de saída analógica);

- Significados das chaves de temperatura baixa e alta no CLP (TSL 101 e TSH 101, respectivamente);

- Sentido das informações na malha de controle;

- Definição de ação inversa da válvula de controle sobre a temperatura em caso de troca térmica com água gelada como fluido de resfriamento.

Por fim, em duas das perguntas foram observadas duas respostas erradas, sendo as de maior frequência de erros. Tais questões eram relacionadas as representações em campo do transmissor de temperatura (TT 101) e da válvula de controle de temperatura (TV 101) e o sentido do sinal de controle que sai do cartão de memória (TY2) e entra na válvula de controle de temperatura (TV 101).

Os resultados podem ser considerados bem satisfatórios, demonstrando que os alunos obtiveram o conhecimento necessário que seria primordial para a construção do P\&ID do projeto de engenharia em equipe desenvolvido ao longo do período da disciplina. A verificação da dificuldade na definição do tipo de sinal, analógico ou digital, de entrada ou saída, levou ao professor explorar um pouco mais exemplos de outras malhas de controle nas aulas seguintes, tais como: controle de vazão via inversor de frequência, controle de pressão via válvula de controle de pressão e intertravamento de motor de bomba via transmissor de nível.

Adicionalmente, foi também construída a lista de IO do tema desenvolvido em equipe. Para maior dinamização e confirmação do conhecimento relativo à definição do tipo de sinal, tal documento foi construído interativamente com cada equipe, com cada aluno respondendo a quantidade e o tipo de sinal de cada equipamento ou instrumento. Nessa atividade verificou-se um elevado índice de acertos de todos os alunos, indicando melhorias nas falhas identificadas no formulário aplicado.

Cabe destacar que as percepções dos alunos são coletadas através de formulários de autoavaliação em cada fase do projeto de engenharia e para cada documento desenvolvido em equipe. No caso do P\&ID, foi citada a complexidade e grau de detalhamento da representação das malhas de controle como dificuldade inicial, até por ser um tema não abordado com frequência em outras disciplinas. Além disso, registrou-se elogios em relação aos formulários elaborados, que possuíam um caráter prático e foi facilitador para o entendimento das malhas de controle.

Outro indicativo da eficiência da abordagem didática-pedagógica através do uso de formulários do Google Forms para ensino de P\&ID foi observado na comparação entre as percepções dos alunos no início e final do período em relação a duas competências técnicas: conhecimento da metodologia de projeto de engenharia e seus documentos específicos; e competência na construção de desenhos de engenharia. Nas autoavaliações realizadas observou-se aumento significativo nas percepções de todos os alunos em relação ao domínio maior das competências técnicas citadas.

$\mathrm{Na}$ autoavaliação realizada foi identificada ainda a percepção dos alunos em relação a dificuldades em outros tópicos relativos ao P\&ID, tais como a definição do tipo de válvula adequada para cada serviços, escolha apropriada do tipo de bomba e definição correta do tipo 
de analisador em medições de correntes específicas. Tais temas podem ser trabalhados futuramente em outros formulários a serem elaborados.

\section{CONSIDERAÇÕES FINAIS}

A utilização da plataforma Google Forms mostrou-se uma ferramenta didático-pedagógica atraente para a intensificação do aprendizado dos alunos sobre o Fluxograma de Engenharia de Tubulação e Instrumentação.

As elevadas médias de acertos dos dois formulários aplicados $(97,0$ e 93,2 \%) demonstrou que os alunos foram previamente habilitados para o desenvolvimento prático do P\&ID do Projeto de Engenharia em equipe.

Foi possível a identificação, através das respostas erradas do formulário, de alguns assuntos nos quais os alunos tiveram maiores dificuldades de entendimento. Por exemplo, a definição do tipo de sinal de alguns instrumentos: digital ou analógico e de entrada ou de saída. Isso possibilitou ao professor planejar outras atividades visando diminuir as dificuldades encontradas.

A eficiência da abordagem também foi verificada nas maiores percepções dos alunos no final do período em relação as competências técnicas de conhecimento da metodologia de projeto de engenharia e seus documentos específicos, bem como a competência na construção de desenhos de engenharia.

\section{REFERÊNCIAS}

BASSANE, Bárbara Carlos; ANTUNES, Marianna Rangel; VILANI, Cecília; CARVALHO, Roberto Bentes. Projeto conceitual e análise econômica preliminar do processo de pervaporação para recuperação do aroma do suco de abacaxi. In: VOIGT, Carmen Lúcia. Impacto das Tecnologias na Engenharia Química 2. 1ª Edição, Paraná: Editora Atena, 2019. P.257-273

DE CARVALHO, Roberto Bentes; DE SOUZA, Francyne Helena; MIRANDA, Rachel Dantas. Rota conceitual e avaliação econômica preliminar de uma planta de cogeração/trigeração de energia a partir de cavaco de madeira e caroço de açaí. In: ANDRADE, Darly Fernando. (Ed. Chefe). Processos Químicos e Biotecnológicos vol.2. 1ª Edição, Belo Horizonte: Editora Poisson, 2019. p.21-31.

FARIAS, Paulo Henrique de Freitas. Informática Educacional: Aplicativos Google Apps for Education como ferramenta de apoio ao professor. In: XVII SEDU Semana da Educação UEL, 2017, Londrina. Anais. Londrina, 2017.

OLIVEIRA, Vanderli Fava. A engenharia e as novas DCNs - Oportunidades para formar mais e melhores engenheiros. $1^{\text {a }}$ Edição, São Paulo: LTC, 2019.

SANTOS, V. Ensino remoto: como potencializar suas aulas com o Google Forms. Disponível em: https://novaescola.org.br/conteudo/19492/ensino-remoto-como-potencializarsuas-aulas-com-o-google-forms. Acesso em: 25 set. 2020.

TAMIETTI, Ricardo Prado. E-book: Engenharia de Projetos Industriais. $1{ }^{\text {a }}$ Edição, Minas Gerais: Editora Engeweb, 2009. 


\title{
APPLICATION OF GOOGLE FORMS AS A DIDATIC AND PEDAGOGICAL TOOL FOR TEACHING PIPPING AND INSTRUMENTATION DIAGRAM (P\&ID)
}

\begin{abstract}
The adoption of active strategies of teaching is recommended by the new curricular guidelines for the Brazilian engineering graduation courses. In this context, the advancement of technology has enabled the utilization of new pedagogical tools, in order to intensify the learning process. In this work, the "Google Forms" platform was used for elaboration of forms about the learning of students of Chemical Process Design, a discipline dedicated to the elaboration of Team Engineering Projects. The engineering drawing, especially the Piping and Instrumentation Diagram (P\&ID), were chosen as topics for evaluation, due to their higher level of complexity. Two Forms were developed and applied to the class of 2020.1, composed of 11 students. The first, containing twelve multiple-choice questions, was about the different areas and connectors of the $P \& I D$ and the second, containing sixteen true or false questions, was about the complete representation in the P\&ID of the specific temperature control loop via the control valve. The utilization of Google Forms presented promising results and a great acceptation from the students, because of its easy and simple graphical interface and due to the availability of a variety of functions for the professor, including the importation of multimedia resources and a detailed statistical result based on the responses. The average percentages of correct answers for the forms were 97.0 and $93.2 \%$, respectively, indicating that students are previously qualified to build the P\&ID of the Engineering Project in a team.
\end{abstract}

Keywords: P\&ID, Google Forms, Active strategy. 